\title{
SQUINELO, ANA PAULA (ORG.). LIVRO DIDÁTICO E PARADIDÁTICO DE HISTÓRIA EM TEMPOS DE CRISE E ENFRENTAMENTO: SUJEITOS, IMAGENS E LEITURAS.
}

1. ED. CAMPO GRANDE: EDITORA LIFE, 2020, 500P.

\section{HECKO, Leandro ${ }^{1}$}

https://orcid.org/0000-0002-1059-854X

Reflexões sobre o Ensino de História e temas a ele correlatos são imprescindíveis em qualquer momento histórico. O que dizer, então, de reflexões em contextos de crises e enfrentamentos, quando os conhecimentos históricos são questionados em sua essência e postos em xeque diante de negacionismos? Tornam-se vitais ao pensamento humano, à liberdade intelectual e à prática de professores de História, agora reconhecidos em sua profissão².

Neste contexto, apresento a resenha do livro organizado por Ana Paula Squinelo, intitulado "Livro Didático e Paradidático de História em tempos de crise e enfrentamento: sujeitos, imagens e leituras". Para tanto, a resenha se desenvolve da seguinte forma: apresentação da autora, características gerais da edição da obra, inserção no contexto de produção no campo do Ensino de História e, por fim, alguns olhares sobre as características temáticas da obra, mostrando seus horizontes de possibilidades reflexivas.

Ana Paula Squinelo é professora do curso de História da Universidade Federal de Mato Grosso do Sul (UFMS), campus de Aquidauana, bem como do Programa de PósGraduação em Estudos Culturais, da mesma universidade e campus. Na UFMS a professora atua em disciplinas como Pesquisa Histórica, Prática Pedagógica, Prática de Ensino, além de orientar estágios obrigatórios do curso de licenciatura de História da instituição onde atua. Coordena projetos de pesquisa voltados ao Ensino de História. Em sua produção, constam inúmeros artigos com temas diversos, entre os quais os principais são Ensino

1 Possui graduação em História pela Universidade Estadual de Londrina (2003), mestrado em História pela Universidade Federal do Rio Grande do Sul (2006), doutorado em História pela Universidade Federal do Paraná (2013) e Pós-Doutorado em Arqueologia pelo Museu de Arqueologia e Etnologia da Universidade de São Paulo (2021). Atualmente é professor da Universidade Federal de Mato Grosso do Sul e docente colaborador do Programa de Mestrado Profissional em Ensino de História - PROFHISTÓRIA/UEMS. E-mail: hecko-leandro.hecko@gmail.com

2 Para informações sobre a regulamentação, acessar: https://anpuh.org.br/index.php/201501-20-00-01-55/noticias2/noticias-destaque/item/6284-sugestoes-para-o-processo-de-registro-dehistoriador Para orientações acerca de como requerer o registro profissional, acessar: https://www. cafehistoria.com.br/historiadores-ja-podem-requisitar-o-registro-profissional-da-categoria/. 
de História e Guerra do Paraguai. Entre os livros, os temas mais recorrentes também são Ensino de História e Guerra do Paraguai.

Em continuidade, a obra que aqui se resenha, faz parte de uma série chamada "Ensino de História - Olhares para além do eixo", sendo seu $4^{\circ}$ volume. Pela ficha catalográfica, a obra conta com 500 páginas, sendo uma "Apresentação" escrita pela própria autora, um "Prefácio" escrito pela professora Márcia Elisa Teté Ramos da Universidade Estadual de Maringá, referência na área de Ensino de História, e uma divisão ampla em duas partes. Na primeira parte, são 17 capítulos com diversos autores. Na segunda parte, tem-se um conjunto de materiais referentes a Circe Maria Fernandes Bittencourt, uma das maiores referências nacionais na área de Ensino de História, composto de uma conferência e uma entrevista.

Da obra, cabe destacar, ainda como informações gerais, de sua constituição plural da escrita, congregando profissionais das seguintes instituições: Universidade Federal do Amapá (UNIFAP), Universidade Federal de Mato Grosso do Sul (UFMS), Universidade Federal de Pernambuco (UFPE), Secretaria de Estado da Educação de Mato Grosso (SEEMT), Universidade Federal de Rondonópolis (UFR), Universidade Federal de Goiás (UFG), Universidade Federal de Mato Grosso (UFMT), Universidade do Estado de Mato Grosso (UNEMAT) e Instituto Federal de Goiás (IFG), somando também com experiências de autores de Portugal. Há uma diversidade de regiões envolvidas, de experiências de Ensino de História em contextos os mais distintos e profícuos, de onde a riqueza da obra é oriunda.

O que dizer em relação à inserção da obra no contexto das publicações gerais sobre o Ensino de História? Sabemos que nesta área as publicações são necessárias e recorrentes, e se constituem em publicações de um autor apenas ou de organizações de obras com diversos outros. O ensino de história tornou-se área de pesquisa a partir de estudos e publicações que datam dos anos 1980 (Ernesta Zamboni, Circe Bittencourt...) e desde então houve inegável aumento de historiadores/as interessada/as em discutir e tratar cientificamente este debate, bem como combater a separação entre ensino e pesquisa na formação em História. Também há o fluxo de publicações de pesquisadores nos mestrados (acadêmicos e profissionais) e doutorados que tratam de temas do Ensino de História, que aumentam o contexto das obras ano a ano. Das mais recentes, trago à memória por exemplo, o relançamento da obra de Circe Maria Fernandes Bittencourt (2018), em formato de e-book, intitulada "Ensino de História: fundamentos e métodos", já clássica no âmbito das licenciaturas em História que a utilizam com frequência, obra fundamental no tocante à 
epistemologia da área de Ensino de História; outra obra que me ocorre neste panorama é a "A História 'Encastelada' e o Ensino ‘Encurralado”” de Eri Cavalcanti (2021), que aborda a questão dos currículos nas licenciaturas brasileiras, a problematização da inserção da disciplina na Educação Básica, a formação de professores, entre outras possibilidades, que afetam diretamente a forma como o Ensino de História se desenvolve. Assim, considero a inserção da obra organizada por Squinelo como uma importante soma ao panorama de publicações da área que, por sua diversidade de autores qualifica ainda mais uma publicação comprometida com temas importantes para os profissionais da área de História.

Entrando especificamente na obra, devo dizer que não irei fazer uma resenha própria dos capítulos, pois a apresentação da obra feita pela autora e constante no livro já o faz de forma satisfatória. Observarei, por sua vez, o seguinte: alguns conhecimentos específicos observados e problematizados, alguns temas atuais e importantes presentes e algumas linguagens constantes entre as reflexões propostas pelos diversos autores do livro.

Primeiramente, cabe dizer sobre o fato de que na obra o livro didático ou paradidático é observado em sua constituição ou em algum recorte específico, de forma que há que subentender que ambos estão sempre no fundo das análises. Outro ponto a se firmar diz respeito ao contexto da obra diante da Base Nacional Comum Curricular (BNCC), publicada em 2018. A BNCC em termos de influência, atua sobre o Programa Nacional do Livro e do Material Didático (PNLD) imprimindo um certo padrão ao que organizará a confecção dos livros pelas editoras que possuem interesse na venda de seus produtos. Dos capítulos constantes no livro, existe apenas um que aborda mais diretamente a BNCC e o horizonte de expectativas que ela pode causar nos livros e materiais didáticos, porém os autores a consideram em suas análises em outros casos.

Em segundo lugar, é importante dizer que no livro há capítulos específicos que refletem sobre a constituição do livro didático, sobre a pedagogia do ensino, formação de professores e recortes sobre a historiografia do Ensino de História, principalmente no Brasil. Desta forma, no âmbito teórico-metodológico apresenta elementos importantes para professores e pesquisadores.

Em relação aos conteúdos específicos presentes em alguns capítulos, temos os seguintes recortes: História dos Estados Unidos, Guerra do Paraguai, História Antiga (Egito e Grécia) e História da América. Entende-se em cada capítulo que aborda cada conteúdo uma problematização da forma como ele está inserido no livro didático, apresentando possibilidades analíticas para seu ensino, exemplificando, em alguns casos, as ocorrências e abordagens. 
Entre os temas atuais importantes, a presença da História das Mulheres, feminismos, a questão do social e do trabalho, a História da África, a História Indígena e a questão do patrimônio e museus mostram também um engajamento das abordagens em uma história problema. Esta história problema posta em tela, reflete temas atuais que geram polêmicas e, diante de novas epistemologias, possibilitam atualização e criticidade em relação ao conhecimento histórico produzido.

Além disso, os capítulos dos livros apresentam uma abordagem plural no tocante às linguagens em que o conhecimento histórico no livro didático pode ser observado, ensinado e analisado. As mais presentes no livro são o cinema, as histórias em quadrinhos e as chamadas Tecnologias da Informação e Comunicação (TICs), que possuem em si diversos formatos de linguagens também. Outras linguagens, como escrita e iconografia também são identificáveis em abordagens dentro da obra. Cabe um destaque para um capítulo específico sobre os livros didáticos e paradidáticos para surdos, que num contexto de inclusão, problematizam a acessibilidade linguística do conhecimento histórico para surdos.

Por fim, à guisa de conclusão, deve-se afirmar que toda obra individual ou coletiva pode implicar ausências de abordagens importantes, lapsos temáticos ou, quando se trata de documentos de políticas educacionais, alguma tendência ao elogio ou crítica. Não obstante, isto reflete a diversidade própria da obra, que a nosso ver é seu ganho, e pluralidade de autores e experiências compartilhadas a partir de suas realidades profissionais ou áreas de interesse. O livro organizado por Ana Paula Squinelo, portanto, deve ser pensado em seu momento de criação e contribuição para a historiografia do Ensino de História, podendo atender a diversos interesses de pesquisadores e professores da área.

\section{REFERÊNCIAS}

BITTENCOURT, Circe Maria Fernandes. Ensino de História: fundamentos e métodos. São Paulo: Cortez Editora, 2018. (e-book)

BRASIL. Ministério da Educação. Base Nacional Comum Curricular - BNCC. Brasília, DF: Ministério da Educação, 2018.

CAVALCANTI, Eri. A História 'Encastelada' e o Ensino 'Encurralado'. Curitiba: CRV, 2021.

Programa Nacional do Livro e do Material Didático (PNLD) disponível em https://www.fnde. gov.br/programas/programas-do-livro com último acesso em 30/04/2021. 